\title{
With growth comes accountability: could a leisure activity turn into a driver for sustainable growth?
}

\section{Valeria Croce}

\author{
Valeria Croce is a Manager in \\ Travel Business Intelligence at \\ the Department of Tourism \& \\ Hospitality Management, \\ MODUL University Vienna, \\ Wien, Austria.
}

\begin{abstract}
Purpose - The purpose of this paper is to retrace the past development of the global tourism sector to identify past drivers of growth and try to understand which factors will shape the sector development in the long term. The paper also intends to initiate a discussion on critical areas the global sector needs to address if it wants to establish as a model for sustainable and inclusive growth.

Design/methodology/approach - This paper analyses the political, economic, socio-cultural and technological factors that influenced tourism growth.

Findings - The global tourism sector has experienced continuous expansion and diversification to become one of the largest and fastest-growing economic sectors in the world. With increased recognition of tourism contribution to economic growth and development, more opportunities will arise for tourism to take centre stage in the political and economic agendas worldwide. Such opportunities can be successfully realised only once the global tourism sector eventually engages to mitigate negative impacts.
\end{abstract}

Research limitations/implications - The paper is based on an extensive review of published literature; hence, it reflects the view major organisations dealing with tourism have on the future development of this sector. The factors included in this analysis have been prioritised based on the sector knowledge of the authors and may not be reflect other viewpoints.

Practical implications - Tourism could establish itself as a model that puts aspects such as the conservation, preservation and protection of the cultural and natural heritage at the heart of economic development. For global tourism to become a driver of socio-economic change, stronger guidance is needed to set priorities that would lead the sector to mitigate its negative impacts. The paper critically discusses some of those aspects that could become policy priorities for the next decades.

Originality/value - The main value of this piece of research is the extended, cross-disciplinary literature of the factors that conducted to the rapid and healthy growth of the tourism sector worldwide.

Keywords International tourism, Sustainable growth, Growth drivers, Long-term forecasts, PEST analysis Paper type Viewpoint

\section{Introduction}

Over the past six decades, tourism has experienced continuous expansion and diversification to become one of the largest and fastest-growing economic sectors in the world. Despite occasional shocks, international tourist arrivals have shown virtually uninterrupted growth from a mere $25 \mathrm{~m}$ in 1950 to $277 \mathrm{~m}$ in 1980 and $935 \mathrm{~m}$ in 2010. The latest count puts international tourist arrivals at 1.323bn worldwide (World Tourism Organization, 2018b).

Improved living conditions and technology innovations have been key drivers of tourism growth along the twentieth century. Rising affluence made tourism services accessible to a larger share of the world population, even though tourism services satisfy needs at the top of Maslow's (1943) pyramid)[1]. Technology innovation in transportation boosted international mobility, as more speedier and cheaper connections were made available. As consumers became better travelled, product diversification and new media helped tourism destinations gain a competitive edge and 
joined in the list of key drivers of sustained tourism growth in the beginning of the twenty-first century. Tight competition stimulated infrastructure investments and product innovation and transformed a trip into a life-changing experience.

As appetite for travel is far from being exhausted, the global tourism sector is set to continue grow at a somewhat slower, but still sustained pace through 2030 (World Tourism Organization, 2011a, b). UNWTO forecasts the number of international tourist arrivals to increase by 3 per cent a year, on average, between 2010 and 2030, compared to an average of 4 per cent a year in the period 1995-2010. The projected growth represents some $43 \mathrm{~m}$ additional arrivals a year. At this pace, the $\mathrm{UN}$ agency forecasts international tourist arrivals to reach 1.8 bn by 2030, nearly double the volume of international arrivals measured in 2011 (World Tourism Organization, 2012a).

Increased volumes will further consolidate tourism role as a driver of development and diversification for economies worldwide. While the direction is set, the approach the global sector will adopt to tap opportunities and respond to challenges will determine the viability of its development in the long run. Tourism-related policies and private investments can steer the sector towards the adoption of a sustainable model that mitigates its negative impacts and protects its key resources, such as the environment, local cultures and diversity. Stronger political leadership is needed to guide the global tourism sector towards a full accountability of its economic, social and environmental impact, and to steer the sector towards a truly sustainable development, which might establish tourism, over time, as a role model for an inclusive and sustainable growth.

A review of those factors that most contributed to the growth of the global tourism sector in the past can stimulate the discussion about which policy objectives should be prioritised to steer the sector towards a sustainable growth model. The reminder of this paper presents a structured review of the past development of the global tourism sector, followed by the analysis of those current trends that are most likely to influence development in the long run. Conclusions offer some stimula to reflect about tourism possible future role as model for sustainable and inclusive growth.

\section{Global tourism development between 1950 and 2010}

During the 1950s, a climate of austerity permeated Western societies, who were paying the high costs of post-war reconstruction, of conflicts engendered by the Cold War (such as the Korean and Vietnam wars), and of the decolonisation process of former European colonies. In advanced economies, tourism was a popular activity among members of the upper and middle classes, but it remained a privilege for the few who could afford it. Social policies and private initiatives, such as holiday funds and camps for workers, helped spreading holiday consumption also among the less affluent segments of the population, especially in post-war Europe (Schumacher, 1890; Kaspar, 1965; Lanquar and Raynouard, 1978; Hachtmann, 2010). International tourist arrivals rose from 25 to $70 \mathrm{~m}$ in just a decade, thanks to resumed security and improving living conditions (World Tourism Organization, 2018a).

Economic prosperity, coupled with business innovation and cultural vivacity, marked Western countries' societies in the 1960s and 1970s. Holidays became accessible to masses, thanks to the combined effect of rising incomes and dwindling prices, these latter pushed down by increased competition, especially in the airline and accommodation sector. Charter airlines (airlines selling transportation by aircraft instead of by seat), and tour operators brought package holidays back in fashion. The single-priced combination of flights, transfers and accommodation was cheaper than each individual component, and rapidly became a popular product. Resorts in the Mediterranean mostly benefitted of this trend, at times when 70 per cent of all international travel from European countries. Travel also became an iconographic activity of the socio-cultural revolution started in 1968. Informal travel, such as backpacking, hitchhiking, caravanning and camping, embodied this spirit and become popular during the 1970s. Two oil shocks (in 1973 and 1979), high inflation and a severe economic situation were not enough to curb that travel euphoria (UN Department of Economic and Social Affairs, 2018b). International tourism grew annually at a rate close to 9 per cent in the 1960 s and 
7 per cent in the 1970s. International tourism volumes reached 166m in 1970 and $277 \mathrm{~m}$ in 1979 (World Tourism Organization, 2018a).

Only the economic recession of the early 1980s could temporarily freeze international tourism growth. The recession started right after the second energy crisis and hit most advanced economies, leaving behind high inflation and unemployment rates. Neoliberal policies became the political response in many advanced economies, which led to the rise of multinational corporations and the relocation of manufacturing industry in emerging economies, mainly in South-East Asia. The economic boom that followed marked lifestyles in advanced economies: people aimed at living longer, acting younger and possessing luxury goods (UN Department of Economic Social Affairs, 2018c). Vacations became a symbol of economic status and pent-up demand for international travel was released. Glamourous holidays - on a cruise, at a ski-resort or at an island resort - became prominent tourism products in the 1980s. New, exotic destinations established alongside traditional tourism destinations in North America and Northern, Western, and Mediterranean Europe. International tourist arrivals grew by 4.2 per cent a year, and $435 \mathrm{~m}$ international arrivals were counted in 1990 (World Tourism Organization, 2018b).

The last decade of the twentieth century was initially marked by the transition from centrally planned to free market economies. The process started in former communist countries in Eastern Europe, after the disintegration of the Warsaw Pact in 1989. This process marked the end of the Cold War, and of the longest periods of peace and prosperity in Europe. The transition also paved the way to the economic and political integration of Europe, which later boosted tourism growth and development in the region. In parallel, Xiaoping introduced the extensive reform at the basis of China's present-day economic performance and tourism positioning (UN Department of Economic and Social Affairs, 2018d).

Another distinctive mark of the 1990s is the rapid evolution of information technology (IT) and globalisation. Most digital technology, which will come into use just a decade later, is marketed for the first time, such as mobile phones, CDs and DVDs. The World Wide Web had just been invented, and only a decade later people surfed on broadband to use online services, such as e-commerce. IT and the internet triggered the development of innovative business models, based on the automation and optimisation of business processes, and by easier access to the global marketplace (Buhalis and Law, 2008). Last-minute offers (e.g. companies marketing unsold seats and packages at a reduced price) and low-cost flights (airlines offering cheaper flights against reduced services) released pent-up demand for travel among the less affluent parts of the population, especially in rapidly emerging economies (Calder, 2003; Dacko, 2004). Supported by positive economic growth and globalisation, technological and business innovations pushed international travel volumes to 626m arrivals by the end of the 1990s (World Tourism Organization, 2018b). Inspired by the Bruntland's (1987) report and the agreement on the Kyoto Protocol (United Nations, 1997) sustainable development and environmental protection entered the agendas of governments and of the international community. This trend was first captured by the youth, which embraced environmentalism and responsible travel in the form of adventure and volunteer travel and eco-tourism (Wearing, 2004; Tomazos and Butler, 2009).

In an increasingly globalised environment, in the first decade of the twenty-first century, the world economy grew at an even faster pace than in the previous decade, despite the climate of growing uncertainty brought by conflicts and crises. International trade expanded further, and more capital flew into emerging economies, which exploited their comparative advantage in terms of costs of production, notably India and South-Asian countries, and to a lesser extent in Eastern European countries. Long-time predicted, economic-giant China broke through, and led a more generalised, rapid catch-up of emerging economies (UN Department of Economic and Social Affairs, 2018a). Increased affluence, coupled with visa facilitation, led to a prosperous development of the tourism sector in emerging economies, primarily supported by a rapid growth of domestic and intra-regional travel flows (Kester and Croce, 2011). Led by emerging economies, international tourists arrivals grew at an average rate of 3.5 per cent per year, achieving the record level of 935m in 2010 (World Tourism Organization, 2018b). The enthusiastic growth of emerging countries contrasted with the growing sense of insecurity and instability that permeated advanced economies. In the aftermath of 9/11 terror attacks to the USA, the escalation of international wars, civil unrest and nuclear threats, and the 
occurrence of exceptional natural disasters, sowed a sense of uncertainty, which peaked during the economic and financial crises at the end of the decade.

The economic turbulence of late 2008 and 2009 caused the first, exceptional decline in the number of international tourist arrivals worldwide. The crisis caused a slowdown in international tourists arrivals in 2008 ( +2 per cent against a long term average of $4-5$ per cent) and a 4 per cent decline in 2009 (Croce, 2016; World Tourism Organization, 2018a, b, c). In 2010, international tourist arrivals worldwide were up by 7 per cent, and marked a new all-time record, with an additional $22 \mathrm{~m}$ arrivals over the former peak year 2008. Tourism's quick recovery in 2010 confirms the sector's resilience in the medium and long term (World Tourism Organization, 2011a, b; 2012a, b).

\section{Drawing lessons from the past: key drivers of tourism growth}

The analysis of those factors underlying growth in global tourism demand has been the object of a vast body of literature. In tourism economic studies, for instance, consensus have been reached on the role played by population size, disposable income, exchange rates (and the relative cost of tourism) and transport costs as key determinants of tourism development from the demand side (for a review, see Witt and Witt, 1995; Lim, 1997, 1999; Song and Li, 2008; Vanhove, 2011).

From a supply-side perspective, tourism started its path to become a global industry in the 1970s, with a Fordist production system based on standardised mass production. With the advent of globalisation and increased worldwide competition, in the 1990s, the global tourism sector switched to a post-Fordist production approach that led to customisation and market segmentation (Richards, 2011). Factors such as technology development, and related business innovations, the increasing liberalisation of economies as well as public and private investments paved the way for an increasingly spread and diversified supply of tourism services worldwide (Ritchie and Crouch, 2003; Crouch and Ritchie, 1999; Gooroochurn and Sugiyarto, 2005; Blanke and Chiesa, 2013). Changes in the external environment, such as large-scale social, economic, political and environmental factors, also contributed to shape tourism development at global level (Organisation for Economic Co-operation and Development (OECD), 2018).

The systematic analysis of these factors can help identify which ones have the highest potential to continue influencing tourism development in the future. Unlocking the mechanism that generates the impact is also a useful exercise to identify some of those emerging trends that might turn into key determinants or game changers in the long run, net of external environment factors and natural hazards affecting tourism growth trajectory (Weber, 2007). In this light, Table I provides an overview of those factors that mostly influenced growth in international tourist arrivals since they were first monitored in the 1950 s.

\section{Will future tourism development be a continuation of the past?}

The coming decades will present destinations significant opportunities, equally matched by challenges, to tap the potential of a healthily growing sector. Shocks and crisis will still temporarily affect tourism development over the next decade, but the long-term trend will remain steadily upwards, as increasing affluence in well-populated world areas will feed a far from exhausted demand for travel, and technology will keep driving innovation. If global volumes increase, their distribution across world regions is going to change. Led by emerging economies, domestic and intra-regional travel is expected to be the most relevant form of travel for the next decade and the following period (World Tourism Organization, 2011a, b). This will bring the diversification process further, with the proliferation and development of new destinations leading to increased competitiveness coupled with challenges to sustainable development, whose principles might be more difficult to observe in developing economies (Tosun, 2001).

A structured review of the factors that mostly influenced the development of modern tourism since its inception may be a useful guide to understand which alternatives patterns of tourism 
Demand-related factors

Population

Affluence

Distance travelled

Relative cost of travel

Time

Social attitudes

Supply (destination)-related factors Connectivity

Marketing

Attractions

Local regulatory framework

Infrastructure

Safety

Investments
The number of departures generated by a market, or a region, is positively related to the size of its resident population. Population characteristics, such as age structure and geographical distribution, also influence travel propensity. The increasing popularity of tourism in densely populated markets opened up to unprecedented opportunities for the global sector development

Households' economic prosperity have been positively relating to tourism demand development over the past decades. People start allocating disposable income in leisure travel only once its level exceeds the threshold marked by the cost of goods and services fulfilling basic needs. Rising affluence in developing economies has been a boost of tourism development since the beginning of the twenty-first century

The income threshold for people to travel tends to increase with the distance travelled, as the monetary cost of travel also increases. This partially explains the pattern, which sees domestic and short-haul travel expanding more rapidly than long-haul trips in emerging markets. Competition on well-travelled routes can dwindle transportation prices and reverse the direct relationship. The low-cost models on short-haul trips has been one of the key factors underlying tourism growth at the end of the twentieth century

The cost of tourism-related goods and services in a country determines the distribution of price-elastic tourism demand across destinations. Inflation and exchange rates, at the origin and at the destination, impact on the relative cost of a trip, hence on demand. Enabled by improved air connectivity and visibility offered by online platforms, the relative cost of travel at the destination has become a major component of destination competitiveness. Yield management techniques offered companies the possibility to exploit location and seasonality factors to improve their price competitiveness

Travel is a time-consuming activity. The amount of days of paid leave and the calendar of public holidays influenced leisure tourism propensity and patterns since its early days. Speedier transportation and flexible time management (e.g. working hours) contribute to reduce the impact discretionary time has on international tourism, as seen with technological improvements in airlines or train connections and the rise of short-breaks since the early 2000s. The tendency to take more frequent breaks resulted in a decrease in the average duration and expenditure per trip

Over the past decades, tourism has turned from an élite to a mass activity and a mirror of individuals' socialstatus, which was reflected into the diversification of tourism products. More recently, tourism for personal purposes has turned into an engaging, if not life-changing, activity undertaken to acquire new skills (e.g. enhancing sport, language, handcraft skills), enhance knowledge (e.g. deep dive into a specific topics) or a spiritual experience. Societal changes such as an ageing population and changes in family structures also contributed to the rise of new products, e.g. targeting multi-generation families or solo travellers

Transport infrastructure is the factor enabling visitors to reach a place, hence a key driver in tourism development. Investments to expand air, rail and road infrastructure contributed to increase the number of destinations on the global tourism map

Marketing made a major contribution to tourism development since the 1950s. Advances made by academics and practitioners, coupled with internet-based and mobile technology development, were key components of the professionalisation and sophistication of destination marketing approaches. Improved visibility, effective targeting and engaging marketing tactics significantly contributed to stimulate demand flows and repeat visits. Increased availability of information improved transparency and supported travellers' decision-making process. Recently, tracking services and mobile technology enabled service providers to establish a close, real-time relationship with customers

Being them leisure or business attractions, natural or cultural, attractions are the trigger for people to visit a place abroad

Given the public nature of key infrastructure and many attractions, the regulatory framework most strongly affects tourism development, the range and quality of tourism products, and the sector competitiveness in the global market

This entails both elements related to mobility at the destination and accommodation and is necessary for the visitor to reach and consume the tourism product. Capacity, quality and innovation are characteristics, which increase the attractive power of a destination

It is a critical factor for tourists visiting a destination, as violence, upheavals or poor health conditions can deter visitors from travelling

Government direct expenditure in tourism is a factor that influences sector's development both directly and indirectly, as a positive sign to private potential investors about the country potential. Industrial policies facilitating foreign investment and business start-up also influence tourism development 
Table I

\begin{tabular}{ll} 
Factors & Comments \\
\hline Property rights & $\begin{array}{l}\text { Property protection is a major issue, especially in developing countries, the lack of which discourages foreign } \\
\text { investors in directed much needed capital into developing destinations, despite incentives such as lower cost of } \\
\text { land and labour }\end{array}$ \\
External environment & $\begin{array}{l}\text { Migration policies influence visitors' ability to visit a foreign country, through visa requirements. Whenever } \\
\text { required, the time and monetary cost of obtaining a visa adds up to the total cost of the trip, which negatively } \\
\text { impacts on tourism demand. Visa requirements vary across countries, as a reflection of a country's international } \\
\text { relations. In general, citizens of advanced, trade-based economies have apparently the fewest visa restrictions, } \\
\text { which influences the flows of departures and limits the growth potential of emerging economies as generating } \\
\text { markets } \\
\text { Climate change and tourism are closely related one another. Climate change can impact on tourism } \\
\text { destinations' attractiveness, but it is also fuelled by tourism growth, as it contributes to GHG emissions. Policy } \\
\text { and management responses have been adopted by international organisations, public administrations, and the } \\
\text { tourism sector at large in the attempt of adapting to as well as mitigating of climate change } \\
\text { Since tourism turned into a global phenomenon, global demand has become more vulnerable to hazards. } \\
\text { Political uncertainties or threats that reduced safety proved to be a significant deterrent especially for long-haul } \\
\text { travel demand. Extreme natural events also negatively impact on a tourism destination image and demand. The } \\
\text { intensification of events related to Climate Change started influencing tourists' preferences for the destinations } \\
\text { most affected by these changes }\end{array}$ \\
Natural and man-made hazards
\end{tabular}

development are more likely to concretise, and which impacts they might have on economies, societies and the environment. This section presents some reasoning on current trends that are most likely to continue impacting on tourism development and influence the course of international tourism development over the next decade.

Economic prosperity and improved connectivity are likely to remain the underlying drivers of tourism growth over the next decade. The slower pace of tourism growth at global level is primarily due to statistic effects. As the base volume of international tourist arrivals increases, a comparatively lower pace of growth still implies large growth in volumes. The same dynamic is observed with GDP growth, as some emerging economies, such as China, have reached a more mature stage, with trickle-down effects on tourism. As more people have already reached the income threshold that allows them to travel internationally, the elasticity of travel to GDP is also expected to decline.

A few other factors stand out as possible growth accelerators that will lead international tourism growth worldwide, as illustrated below.

\subsection{An IT-driven paradigm shift}

Over the next decades, the deepest changes in the tourism sector will be driven by the rapid evolution of IT, and the related paradigm shift in tourism product development and service delivery. Much of world economic foundation is increasingly internet- and computer-based, as technology has spread over every aspect of life and considerably modified patterns of production and consumption (Gretzel et al., 2006, 2015; Liang et al., 2017). Due to the intangible and experiential nature of tourism, technology will remain a key driver of innovation and growth. The tourism sector proved to be an early adopter of technology innovations, and its capability to generate spill-over effects across large as well as small tourism companies along the value chain is expected to lead to more, significant improvements and disruptions over the next years.

As mobile devices have become smarter and more powerful, they are likely to remain the dominant medium for communication, information sharing and access to services. The convergence of different media into mobile devices provides access to a virtually infinite range of information and services, to be withdrawn upon necessity (Liang et al., 2017). This radically changed the way visitors assemble, access and purchase tourism-related services along the traveller journey, as a seamless experience across different service 
providers. In just a decade, dynamic packaging (a method that enables consumers to build a fully personalised travel package), business-to-consumer communication powered by artificial intelligence (such as customer service and marketing) will turn from innovation into sector standards (OECD, 2018). This demand-driven change will require innovative, lean business models enabling cross-national, flexible partnerships, which, in turn, will require suitable changes in the regulatory framework, across multiple levels of governance.

Enabled by technology, travellers will also be increasingly involved in the "co-creation" of their holiday experience (Buhalis and Amaranggana, 2015). Unique landmarks and landscapes may not loose strength as triggers to visit a specific destination, but a destination's ability to attract visitors will increasingly depend on its capability to generate tourism ecosystems, where experiential tourism products can flourish. Pine and Gilmore (1999) described experiences as the next step to differentiate services in contemporary global value chains, as other characteristics are no longer sufficient for consumers to discriminate among products and services. Tourism has been at the forefront of the experience economy, as the holiday experience is the ultimate benefit of the consumption of goods and services at a destination during a holiday (Haemoon et al. , 2007; Croce and Maggi, 2007; Liberato et al., 2018). Enabled by digital technologies, experience-based industries can transform locally bound, authentic services into unique, augmented experiences that actively engage consumers in the cocreation of the experience itself. Experiential tourism will also offer new opportunities to embrace a sustainable tourism development: supported by integrated strategies for destination development, experiential tourism products can support a virtual fruition of fragile natural and cultural attractions, redistribute tourism flows outside mainstream destinations and contribute to regenerate peripheral economies.

Virtual reality is one of the IT-driven innovations that are most suitable to enrich tourism experiences. Virtual reality proved particularly valuable as a complement to travel, and particularly so in areas such as marketing, travel planning and management, entertainment, education, accessibility, but also heritage preservation. It offers useful applications for the development of tourism products, and will continue do so as it evolves (Guttentag, 2010). Virtual reality offers a full immersion in the proposed reality, hence a powerful, manageable experience, and countless examples can be found of online travel agencies, destinations, hotels and other tourism suppliers who apply virtual reality to enrich their marketing message or offer, as, for instance, virtual-guided tours or gamification and geochasing. More debatable is the development of virtual reality as substitute of actual travel, as tourists' attitude towards authenticity seem to remain unvaried over time and across destinations[2]. Governments preparedness, especially at local level, to identify barriers and provide legislative and financial support to start-ups in emerging sectors like this will be pivotal to enable the growth potential of IT-driven innovation.

De-intermediation is another outcome of the IT-related paradigm shift. While tourism transactions were initially of a B2B or B2C nature, a more recent trend is the entry of alternative suppliers through peer-to-peer (P2P) platforms, where private persons offer products and services to others through an intermediary platform run by an organisation or a company (World Tourism Organization, 2017). This innovative approach to business, referred to as platform (World Tourism Organization, 2017) or collaborative (European Commission, 2018) or sharing (OECD, 2018) economy, offers greater choice to travellers and new opportunities to tourism entrepreneurs, but it is also in its infancy for what concerns rules and policies governing new business models (see e.g. European Commission, 2017). The way legislators will deal with relevant regulatory and economic aspects of the collaborative economy will strongly impact on its future development and contribution to tourism diversification, innovation, convenience and ultimately growth.

As visitors' use of technology has increased, large information about their behaviour, preferences and opinions becomes available in a digital format. The gathering, analysis and storage of massive volumes of data on computerised databases is a major asset for market segmentation and customer relationship management. Tracking technologies provide high-resolution spatial and temporal data that enable policy makers and private businesses track visitors' flows and preferences more precisely, which enables the implementation of a 
wide range of measures, from tailored marketing tactics to flow and congestion management. Public and private investments in infrastructure are key to enable such technological shift, as ubiquitous, wireless connection is the factor enabling the IT-related growth potential.

Future regulation on the production and use of digital data will be both a key enabling factor and a game changer. The issue of data protection recently gained momentum since newspapers suggested that a political consultancy, Cambridge Analytica, had obtained detailed data about Facebook users, which were allegedly analysed and shared with third parties (The Economist, 2018). This scandal initiated a public debate on ethical and legal boundaries to gather data, which was further fuelled by the timely enforcement of the European Union's General Data Protection Regulation (GDPR), long-before planned for a few months after the scandal. GDPR is possibly the most compelling data-protection package that will shape how the digital data business will develop over the next decades. Compliance with a consumer-centric regulation is due to increase transparency, hence customers' trust, and will also allow for improved control along the digital data production chain. Yet, stricter regulations will also introduce new costs and red tape for companies, possibly limiting the economic growth potential of this new emerging sector of the economy. One possible scenario is that the current regulation will introduce a policy disruption in the sector generating new business models thinking beyond compliance with regulations.

\subsection{Mobility as a service}

Transport and tourism sector are closely related, and changes in the transportation sector will continue generate impact on tourism development. Recently, cities around the world have experimented new ways of delivering transportation services to their citizens. These pilots cover different aspects of mobility, ranging from integrated public transportation to car-pooling. One of the driving forces underlying this trend is the shift from ownership to use, which is central to innovation in other tourism-related sectors (World Tourism Organization, 2017). Another main driver are congestion issues arising from the continued trend towards the urbanisation of world population. A third factor is the increased availability of data accessible from the integration of services on mobile devices, as mobility as a service solutions require a data-driven, user-centred paradigm, powered by the growth of smartphones (Goodall et al., 2017). While this might not have a major impact on long-distance transportation, new frontiers will open to the discovery of new places during short holidays and put pressure on traditional transport providers towards multi-modality and integration of different modes of transport.

\subsection{Climate-change response and its trickle-down effects on tourism}

Climate change stands out as probably the factor with the most significant and uncertain impact on tourism future development through 2030. Acceleration in the global response to climate change would strongly impact on tourism production and consumption patterns, yet the possibility and extent of this response is still hard to predict. World leaders' commitment to strengthen the global response to the threat of climate change, of which the signature of the Paris Agreements (UNFCCC, 2015) is the most visible and recent sign, introduces a new variable in the energy puzzle, with multiple trickle-down effects on the tourism sector. If tougher energy legislation is introduced in those fast-growing economies that still heavily rely on carbon and fossil fuels for industry production and export, the shift towards alternative energy sources would have major repercussions on economic growth. Income-elastic tourisms demand from these fast-growing markets would be consequently affected. The mere possibility that tougher legislation on fossil fuels might be introduced might already impact on business operating costs, especially for vectors with a large carbon footprint, as they would factor the risk of facing strict environmental regulations with limited notice in their long-term development strategies.

Tourism is both a vector and a victim of climate change (Cabrini et al., 2009). While some tourism sub-sectors actively contribute to the warming process, effects like rising sea levels, 
desertification, deforestation or the melting of snow and glaciers hurt the tourism economy. This is a strong incentive for tourism policy makers to embrace an economic transformation towards a greener economy, to mitigate tourism impact on the environment, and act as a lead agent towards the greening of the overall economy. The European Commission, for instance, is actively studying the impact of climate change on tourism (Amelung and Moreno, 2009) and supports initiatives that incentive European policy makers with both mitigation and adaptation policies (e.g. through the European Destinations of Excellence programme[3] or the Award for Sustainable Cultural Tourism Destination[4]). Yet, the gap between the knowledge acquired on climate change and its use in public policies and decision making is still wide (World Bank, 2016), and more effort should be made in this direction, not last as consumers are increasingly critical about the environmental impact of their travel. The pressure to adopt greener tourism practices will also come from visitors. Growing concern about natural resources depletion and climate change is already leading towards a more responsible and environmental-friendly tourism consumption. This provides a strong case for governments as well as the private sector to engage in this economic transformation.

\subsection{Upskilling tourism career pathways}

Investing in human resources will also stand out as a crucial element to increase the profitability and competitiveness of visitor economies in the global marketplace. Tourism is a labour-intensive sector, yet it is scarcely attractive to skilled labour force. The seasonal and casual nature of many tourism activities results in low wages, high turnover and lack of long-term career opportunities. This is reflected in the typical pyramid-shaped structure of the tourism labour market, with a vast majority of workers employed in low-skill and low-income jobs. High turnover presents high costs to businesses, as a missed opportunity to capitalise on initial training and work experience. The outlook for the sector might look even darker, as competition for qualified labour force becomes fiercer, especially in new social science jobs that are vital to deliver tailor-made, high-quality experiences to visitors. Next to improving wage and work conditions, the tourism sector is called to build rewarding careers that attract and retain high calibre human resources. To tackle this problem, in 2017 the European Commission funded the project IdEATE[5], an initiative to improve the employability and apprenticeship of young job seekers in the tourism sector and improve the profile of tourism careers in the sector.

Jobs in the tourism sector are very diverse and sometimes serve as a gateway to the labour market for the most vulnerable segments of the population, such as young jobseekers, migrants or unemployed people seeking re-employment. The UN sustainable development goals stress the use of local labour and suppliers as key levers to boost local development and infrastructure (World Tourism Organization, 2016). A forward-looking tourism sector therefore needs to follow this example and seriously address the decent work deficit, especially in areas were legislation is deficient, or face the prospect of losing human resources towards other sectors.

\subsection{Improve the balance between tourism global and local dimensions}

Through increased mobility and technology development, societies have become increasingly interconnected, and share a global culture. Instead of a straight homogenisation of cultures, the globalisation process has led to the coexistence of a globalised culture next to the appreciation of local diversities.

Tourism best embodies this phenomenon, as it lives of its international dimension and of local specificities. While cultural diversity triggers people to travel internationally, the homologation of quality standards meets their expectation to feel at home away from home. While trade liberalisation stimulates competitiveness and facilitates foreign investments, tourists shy away from commoditised tourist services and demand authentic experiences. To face the challenge posed by the increasingly pervasive globalisation process, the tourism sector needs to find a balance between its global and local dimension, and avoid being drowned in the complexities that ensue.

Over the next decade, globalisation will continue act as a force pushing towards the increasing liberalisation of trade and transport, with positive effects on tourism growth. In air transport, a 
large-scale business where the international dimension and economies of scale are necessary to remain competitive, horizontal integration and business innovation will remain key drivers for airlines to improve efficiency and gain a competitive edge, enhancing the value for money of services delivered to consumers. Consolidation and innovation are likely to be the response of the accommodation sector to the aggressive competition made by $\mathrm{P} 2 \mathrm{P}$ accommodation services, enabled by the new platform economy (World Tourism Organization, 2017). Again, the pressure of global competition is expected to initiate a process of rejuvenation in a rather static sector.

In parallel, technology development marks the end of the mass-production era and gives way to mass-customisation. Tailored products shift the focus from price to benefits, offering destinations means to become more attractive towards high-spending visitors. Yet, the personalisation of the tourism product at global scale requires high levels of integration and coordination at the destination. The challenge for tourism businesses is to present the integrated offer from a consumer perspective, with flexibility, transparency and personalisation as priority characteristics. Those who will embrace technological development will be able to deliver personalised services, with global practices coexisting next to local traditions.

\section{Tourism as a driver of change?}

Growing at the pace forecast by UNWTO (2011), tourism is set to establish itself as a relevant significant sector in an increasing number of countries worldwide. Tourism currently accounts for 10 per cent of global GDP and its business volume equals, or even surpasses, that of oil exports, food products or automobiles (World Tourism Organization, 2017). As more and more economies opened up to tourism as a way to relaunch or diversify economies (see e.g. Arab countries' strategic vision for the year 2020; Mortimore, 2007) or rejuvenate depopulated rural areas, tourism economic importance to create jobs, increase export revenues and stimulate infrastructure development will further consolidate. According to World Tourism Organization (2018c), "continued growth and deepening diversification [...] have turned tourism into a key driver for socio-economic progress".

If the global tourism sector is to establish itself as such a key driver of change, it could also become a role model for a new approach to economic development that puts the valorisation of intangibles, such as the conservation, preservation and protection of cultures or the environment, at the heart of economic development. Natural and cultural resources are the lifeblood of tourism, and while tourism contributes on one side to protect the natural and cultural heritage of a destination, not last securing its value, visibility and profitability, tourism can also become its main cause of disruption. Sustainability, especially its social and environmental pillars, is probably the most manifest paradox of this global sector. Faced with climate change and increasing pressure to contain the negative impact of so-called "overtourism", the global tourism sector is demanded to react and transform challenges into new opportunities for growth. As one of the most promising drivers of growth for the world economy, the adoption of sustainable practices in the sector is critically important not only to lead by example, but especially for the trickle-down effects on the many sectors of the economy intertwining with the visitor economy.

A few other lessons could be drawn from the past development of the global tourism sector, as inspiration for its and likely future and for economic development in general. In a world changing at un unprecedented pace and scale, the tourism sector has been characterised by the early and speedy adoption of technology innovations, even among its micro and small enterprises. The early adoption of new technologies initiated disruptive business-model innovations (e.g. low-cost airlines or peer-to-peer accommodation) that stimulated competitiveness and initiated new cycles of growth. The rapid spread of innovation along the value chain, explained by the bundled nature of a tourism experience, enabled specialisation and innovative product development in local clusters. This virtuous behaviour could inspire the rapidly emerging value chains and economic clusters, which evolve from cross-sectoral collaboration, to stimulate innovation and economic growth in other sectors of the economy. 
Another distinctive trait of tourism is its capability to create connections between international markets and the local realities where it spreads. Tourism satisfies human interest in discovering different places and cultures; hence, it is best placed to connect internationally spread demand with local supply. Potentially, an example for other sectors of the economy on how to establish a valid local-global nexus, the global tourism sector should embrace development patterns that mitigate the negative impacts that derive thereof. An example is given by IT innovations: if some innovations helped preserving fragile sites (e.g. through virtual reality), some others introduced new business standards which antagonise the diversifying role of the tourism sector. The development of online travel agencies, for instance, generated high value for consumers, but flattened accommodation supply towards their standard requirements. The monopsony established by these large groups can seriously undermine the sector capability to contribute to local economies being enriched by the diversity intrinsic in the place where tourism flourishes.

Recognition as key driver of socio-economic progress could draw from tourism significant contribution to employment, one of its strongest ties to economic development. Tourism is one of most labour-intensive economic sectors, a factor that has been brought up by governments and international organisations to justify heavy investments for its development. Much attention is currently given to the opportunities offered by IT developments to create more and better jobs for the tourism sector. The rising need for an educated workforce, such as data scientists and e-media managers, certainly contributes to introduce new appealing careers to professionals attracted by a job in tourism. Yet, innovations such as the robotisation of services and the spreading use of artificial intelligence (e.g. in customer service) are set to replace workers at the base of the tourism workforce pyramid, where large volumes of low-skilled workforce (e.g. first-time job seekers, migrants, women) are employed. This recent development could seriously undermine tourism potential to contribute to economic growth, and policies addressing the upskill of the tourism sector and investments on IT innovation should carefully assess the costs and benefits on employment.

The above calls for a better integration of policies at multiple levels. Integrated multi-level governance is another distinctive trait of the tourism sector that is increasingly a requirement across all sectors of the economy. The simultaneously global and local dimension of international tourism requires coordination and a shared vision across multiple levels of governance. While not all destinations have such a system in place, examples of multi-level governance are multiplying across destinations worldwide. One further step must be taken to better integrate tourism into national development plans, positioning tourism as a key propeller of economic development or simply a support to other development priorities, depending on the economic fabric of the destination. This requires continued efforts to understand the intertwining of tourism with other sectors across different economies.

A correct measurement of tourism and its economic impact would be crucial to escalate the role of tourism to a key driver of development. Over the past, considerable advances have been made in this area by academics and international organisations, which led to the adoption of international frameworks for the measurement of tourism, the Tourism Satellite Account (UN, 2008a) and related International Recommendations on Tourism Statistics (UN, 2008b) being the most notable attempt to create worldwide standards. A vast body of literature provides indications about the progress which is still needed for these international frameworks to deliver an effective measurement of the sector performance (see e.g. Jones and Munday, 2008; Smeral, 2006; McCabe, 2006). One aspect to add to the list concerns the very basic definition of tourism. In a world marked by increasing levels and diversified forms of international mobility, the one year threshold, to distinguish between tourism and migrants, records as tourism forms of mobility that could also fit the definition of short-term migration and circular migration (UNECE, 2016, p. 17). As a new mobility paradigm gets established (Urry, 2016), the need arises for integrated statistical frameworks that return a conceptually honest and realistic picture of different form of mobilities.

With growth comes accountability, and tourism, one of the world's fastest-growing sectors, is no exception. With increased recognition of its contribution to economic growth and development, more opportunities will arise for tourism to take centre stage in the political and 
economic agendas worldwide. Such opportunities can be successfully realised only once the global tourism sector eventually engages to mitigate negative impacts, notably on host communities and the environment, and takes the lead in the path towards a more inclusive, stronger and more sustainable growth. Stronger and more integer political guidance from international organisations and governments is needed to achieve consensus on tourism forthcoming priorities, with the support of practitioners and academics, who need to maintain their active role in guiding the sector to avoid complacency and achieve its full potential.

\section{Notes}

1. The UN official definition of tourism covers all trips made for personal (i.e. leisure, visiting friends and relatives or spiritual) and professional (business) purposes. This paper focusses almost exclusively on tourism for personal purposes.

2. It should also be mentioned that a virtual visit that does not imply displacement from the place of usual residence would not count as a tourism activity.

3. www.ec.europa.eu/growth/eden

4. www.europa.eu/cultural-heritage

5. www.www.tourismcareers.eu

\section{References}

Amelung, B. and Moreno, A. (2009), "Impacts of climate change in tourism in Europe, PESETA-tourism study", JRC Scientific and Technical Reports EUR, 24114.

Blanke, J. and Chiesa, T. (2013), "The travel \& tourism competitiveness report 2013", World Economic Forum, Geneva.

Bruntland, G.H. (1987), "Our common future: report of the world commission on environment and development", World Commission on Environment and Development.

Buhalis, D. and Amaranggana, A. (2015), "Smart tourism destinations enhancing tourism experience through personalisation of services", in Tussyadiah, I. and Inversini, A. (Eds), Information and Communication Technologies in Tourism 2015, Springer International Publishing, Lugano, pp. 377-89.

Buhalis, D. and Law, R. (2008), "Progress in information technology and tourism management: 20 years on and 10 years after the internet - the state of eTourism research", Tourism Management, Vol. 29 No. 4, pp. 609-23.

Cabrini, L., Simpson, M. and Scott, D. (2009), “From Davos to Copenhagen and beyond: advancing tourism's response to climate change", available at: www.sdt.unwto.org (accessed 21 September 2018).

Calder, S. (2003), No Frills: The Truth Behind The Low-Cost Revolution in The Skies, Virgin Books Limited, London.

Croce, V. and Maggi, R. (2007), "From the ideal to the real destination: tourists' location choice for holiday experience", in Bieger, T. and Keller, P. (Eds), Productiveness in Tourism, ESV, Berlin, pp. 69-81.

Croce, V. (2016), "Can tourism confidence index improve tourism demand forecasts?", Journal of Tourism Futures, Vol. 2 No. 1, pp. 6-21.

Crouch, G.I. and Ritchie, J.B. (1999), "Tourism, competitiveness, and societal prosperity", Journal of Business Research, Vol. 44 No. 3, pp. 137-52.

Dacko, S.G. (2004), "Marketing strategies for last-minute travel and tourism: profitability and revenue management implications", Journal of Travel \& Tourism Marketing, Vol. 16 No. 4, pp. 7-20.

European Commission (2017), "Consultation on the collaborative economy in the tourism accommodation sector", available at: https://ec.europa.eu/docsroom/documents/24224?locale=en (accessed 21 September 2018).

European Commission (2018), "Collaborative economy", available at: http://ec.europa.eu/growth/singlemarket/services/collaborative-economy_en (accessed 21 September 2018). 
Goodall, W.F., Dovey, T., Bornstein, J. and Bonthron, B. (2017), "The rise of mobility as a service”, available at: www2.deloitte.com/content/dam/Deloitte/nl/Documents/consumer-business/deloitte-nl-cb-ths-rise-ofmobility-as-a-service.pdf (accessed 21 September 2018).

Gooroochurn, N. and Sugiyarto, G. (2005), "Competitiveness indicators in the travel and tourism industry", Tourism Economics, Vol. 11 No. 1, pp. 25-43.

Gretzel, U., Fesenmaier, D.R. and O'leary, J.T. (2006), "The transformation of consumer behaviour", in Buhalis, D. and Costa, C. (Eds), Tourism Business Frontiers, Routledge, Oxford.

Gretzel, U., Sigala, M., Xiang, Z. and Koo, C. (2015), "Smart tourism: foundations and developments", Electronic Markets, Vol. 25 No. 3, pp. 179-88.

Guttentag, D. (2010), "Virtual reality: applications and implications for tourism”, Tourism Management, Vol. 31 No. 5, pp. 637-51.

Hachtmann, R. (2010), "Tourismus und Tourismusgeschichte”, available at: https://zeitgeschichte-digital.de/ doks/frontdoor/index/index/docld/312 (accessed 21 September 2018).

Haemoon, O., Fiore, A.M. and Jeong, M. (2007), "Measuring experience economy concepts: tourism applications", Journal of Travel Research, Vol. 46 No. 2, pp. 119-32.

Jones, C. and Munday, M. (2008), "Tourism satellite accounts and impact assessment: some considerations", Tourism Analysis, Vol. 13 No. 1, pp. 53-69.

Kaspar, P.D.C. (1965), "Strukturelle Veränderungen im schweizerischen Fremdenverkehr zufolge Wandlungen der Reisegewohnheiten”, The Tourist Review, Vol. 20 No. 1, pp. 4-10.

Kester, J. and Croce, V. (2011), "Tourism development in advanced and emerging economies: what does the travel \& tourism competitiveness index tell us", in Blanke, J. and Chiesa, T. (Eds), The Travel and Tourism Competitiveness Report (2011), World Economic Forum, Geneva, pp. 45-52.

Lanquar, R. and Raynouard, Y. (1978), Le Tourisme Social et Associatif, Presse Universitaire de France, Paris.

Liang, S., Schuckert, M., Law, R. and Masiero, L. (2017), "The relevance of mobile tourism and information technology: an analysis of recent trends and future research directions", Journal of Travel \& Tourism Marketing, Vol. 34 No. 6, pp. 732-48.

Liberato, P., Alen, E. and Dalia, L. (2018), "Smart tourism destination triggers consumer experience: the case of porto", European Journal of Management and Business Economics, Vol. 27 No. 1, pp. 6-25.

Lim, C. (1997), "Review of international tourism demand models", Annals of Tourism Research, Vol. 24 No. 4, pp. 835-49.

Lim, C. (1999), "A meta analysis review of international tourism demand", Journal of Travel Research, Vol. 37 No. 3, pp. 273-84.

McCabe, S. (2006), "Who is a tourist?", Tourist Studies, Vol. 5 No. 1, pp. 85-106.

Maslow, A.H. (1943), "A theory of human motivation”, Psychological Review, Vol. 50 No. 4, pp. 370-396.

Mortimore, R. (2007), The Future of Travel and Tourism in The Middle East - A Vision to 2020, Reed Travel Exibitions, London.

Organisation for Economic Co-operation and Development (OECD) (2018), Tourism Trends and Policies 2018, OECD, Paris.

Pine, B.J. and Gilmore, H.J. (1999), The Experience Economy: Work is Theatre \& Every Business is a Stage, Harvard Business Press, Boston, MA.

Richards, G. (2011), "Tourism trends: tourism, culture and cultural routes, cultural tourism trends in Europe: a context for the development of cultural routes", in Khovanova-Rubicondo, K. (Ed.), Impact of European Cultural Routes on SMEs' Innovation and Competitiveness, Council of Europe Publishing, Strasbourg, pp. 21-39.

Ritchie, J.B. and Crouch, G.I. (2003), "The competitive destination: a sustainable tourism perspective", CABI, Oxon.

Schumacher, B. (1890), Ferien. Interpretationen und Popularisierung eines Bedürfnisses. Schweiz 1890-1950, Böhlau Verlag, Vienna. 
Smeral, E. (2006), "Tourism satellite account: a critical assessment”, Journal of Travel Research, Vol. 45 No. 1, pp. 92-98.

Song, H. and Li, G. (2008), "Tourism demand modelling and forecasting - a review of recent research", Tourism Management, Vol. 29 No. 2, pp. 203-20.

The Economist (2018), "The antisocial network", The Economist, available at: www.economist.com (accessed 21 September 2018).

Tomazos, K. and Butler, R. (2009), "Volunteer tourism: the new ecotourism?", Anatolia, Vol. 20 No. 1, pp. 196-211.

Tosun, C. (2001), "Challenges of sustainable tourism development in the developing world: the case of Turkey", Tourism Management, Vol. 22 No. 3, pp. 289-303.

UN Department of Economic and Social Affairs (2018a), "WESS full report", available at: www.un.org/ development/desa/dpad/document_gem/wess-report/wess-full-report/ (accessed 21 September 2018).

UN Department of Economic and Social Affairs (2018b), "World economic and social survey archive: 1970-1979", available at: www.un.org/development/desa/dpad/publication/world-economic-and-socialsurvey-archive-1970-1979/ (accessed 21 September 2018).

UN Department of Economic Social Affairs (2018c), "World economic and social survey archive: 1980-1989", available at: www.un.org/development/desa/dpad/publication/world-economic-and-social-survey-archive1980-1989/ (accessed 21 September 2018).

UN Department of Economic and Social Affairs (2018d), "World economic and social survey archive: 19901999", available at: www.un.org/development/desa/dpad/publication/world-economic-and-social-surveyarchive-1990-1999/ (accessed 21 September 2018).

UNECE (2016), "Defining and measuring circular migration", available at: www.unece.org (accessed 21 September 2018).

UNFCCC (2015), "Report of the conference of the Parties on its twenty-first session, held in Paris from 30 November to 13 December 2015", Addendum. Part Two: Action taken by the Conference of the Parties at its twenty-first session, available at: https://unfccc.int/resource/docs/2015/cop21/eng/10.pdf (accessed 21 September 2018).

United Nations (1997), United Nations Framework Convention on Climate Change, United Nations, Kyoto.

United Nations (2008a), International Recommendations for Tourism Statistics, United Nations, New York, NY.

United Nations (2008b), Tourism Satellite Account: Recommended Methodological Framework, United Nations, Madrid.

Urry, J. (2016), Mobilities: New Perspectives on Transport and Society, Routledge, New York, NY.

Vanhove, N. (2011), The Economics of Tourism Destinations, Routledge, London.

Wearing, S. (2004), "Examining best practice in volunteer tourism", in Stebbins, S. and Graham, M. (Eds), Volunteering as Leisure/Leisure as Volunteering, An International Assessment, CABI, Cambridge.

Weber, F. (2007), "Natural hazards: increasing challenges for tourism destinations", available at: www.esade. edu/cedit2007/pdfs/papers/pdf4.pdf (accessed 21 September 2018).

Witt, S.F. and Witt, C. (1995), "Forecasting tourism demand: a review of empirical research", International Journal of Forecasting, Vol. 11 No. 3, pp. 447-75.

World Bank (2016), "How to make the tourism sector more climate resilient", available at: www.worldbank. org/en/news/press-release/2016/06/01/how-to-make-the-tourism-sector-more-climate-resilient (accessed 21 September 2018).

World Tourism Organization (2011a), Tourism Towards 2030 - Global Overview, UNWTO, Madrid.

World Tourism Organization (2011b), UNWTO Tourism Highlights, UNWTO, Madrid.

World Tourism Organization (2012a), UNWTO Tourism Highlights, UNWTO, Madrid.

World Tourism Organization (2012b), UNWTO World Tourism Barometer, Vol. 10 No. 6, UNWTO, Madrid.

World Tourism Organization (2016), The Tourism Sector and the Sustainable Development Goals - Responsible Tourism, A Global Commitment, UNWTO, Madrid. 
World Tourism Organization (2017), New Platform Tourism Services (or the so-called Sharing Economy) - Understand, Rethink and Adapt, UNWTO, Madrid.

World Tourism Organization (2018a), "Tourism statistics", available at: www.unwto.org (accessed 10 January 2018).

World Tourism Organization (2018b), UNWTO World Tourism Barometer, Vol. 16 No. 3, UNWTO, Madrid.

World Tourism Organization (2018c), "Why tourism?", available at: www2.unwto.org (accessed 12 August 2018).

\section{Further reading}

Chen, J.S., Huang, Y.C. and Cheng, J.S. (2009), "Vacation lifestyle and travel behaviour”, Journal of Travel \& Tourism Marketing, Vol. 26 No. 5, pp. 494-506.

Szabo, L., Ciscar Martinez, J.C., Amelung, B. and Moreno, A. (2009), "Impacts of climate change in tourism in Europe: PESETA-tourism study: JRC scientific and technical reports”, European Union, Brussels.

World Tourism Organization (2014), International Tourism Trends in EU-28 Member States, UNWTO, Madrid.

\section{Corresponding author}

Valeria Croce can be contacted at: valeria.croce@icloud.com

For instructions on how to order reprints of this article, please visit our website: 